\title{
AN OVERVIEW OF HYFIE TECHNICAL RESEARCH PROJECT: CROSS TESTING IN MAIN EUROPEAN HYPERSONIC WIND TUNNELS ON EXPERT BODY
}

\author{
Jean-Philippe Brazier $^{(1)}$, Jan Martinez Schramm ${ }^{(2)}$, Sébastien Paris ${ }^{(3)}$, Thomas Gawehn ${ }^{(4)}$ \\ (1) ONERA DMAE, B.P. 74025, 31055 Toulouse Cedex, France, E-mail: Jean-Philippe.Brazier@onera.fr \\ ${ }^{(2)}$ DLR, Bunsenstrasse 10,D-37073 Göttingen, Germany, E-mail: Jan.Martinez@dlr.de \\ ${ }^{(3)}$ VKI, 72 chaussée de Waterloo, Rhode-St Genèse, Belgium, E-mail: Paris@vki.ac.be \\ (4) DLR, Linder Höhe, D-51147 Cologne, Germany, E-mail: Thomas.Gawehn@dlr.de
}

\begin{abstract}
HyFIE project aimed at improving the measurement techniques in hypersonic wind-tunnels and comparing the experimental data provided by four major European facilities: DLR HEG and H2K, ONERA F4 and VKI Longshot. A common geometry of EXPERT body was chosen and four different models were used. A large amount of experimental data was collected and compared with the results of numerical simulations. Collapsing all the measured values showed a good agreement between the different facilities, as well as between experimental and computed data.
\end{abstract}

\section{INTRODUCTION}

The Technical Research Project HyFIE (short cut for Hypersonic Facility Instrumentation Enhancements for improved flight extrapolation and scaling) was initiated and funded by the European Space Agency [1]. Its aim was to provide a systematic comparison of the experimental data gathered on a same body in the main European hot and cold hypersonic wind-tunnels and then to evaluate the capability of ONERA and DLR to reproduce the tests by numerical simulation, using their respective codes CELHYO $3 D$ and TAU.

This project was carried out by ONERA, DLR and VKI under ONERA's coordination. The facilities involved were ONERA F4, DLR HEG and H2K and VKI Longshot. The common body to be tested was ESA vehicle Expert [2][3][4]. This geometry has a blunt nose and four plates with deflected flaps (see Fig. 1). Four different models were used, one existing and three new ones which were designed and manufactured during the project. The main people involved in HyFIE project were:

- ESA: Jean Muylaert, Louis Walpot, José Longo

- ONERA/DMAE: Jean-Philippe Brazier, Christian Pélissier, Jean-Luc Vérant

- ONERA/F4: Paul Viguier, Julien Garraud, Jacques Soutadé

- ONERA/DMPH: Ajmal Mohamed

- DLR Göttingen: Jan Martinez Schramm and HEG team

- DLR Cologne: Thomas Gawehn, Ali Gülhan and H2K team
- DLR Braunschweig: Bodo Reimann

- VKI: Sébastien Paris and VKI team

The project started in October 2007 and ended in January 2012. Delay was caused by HEG model manufacturing and a severe electrical failure on F4 facility, but all the planned test campaigns were however achieved.

\section{DESCRIPTION OF THE PROJECT}

\subsection{Experimental facilities}

Two high-enthalpy facilities were used, F4 and HEG, where real gas effects can be observed. Beside, two low-enthalpy facilities were also used, Longshot and $\mathrm{H} 2 \mathrm{~K}$, where the fluid generally behaves like a perfectgas.

Located at ONERA Fauga-Mauzac centre, F4 is a hotshot wind-tunnel, in which the gas is heated by an electric arc before blowing into the nozzle. A peak power of $150 \mathrm{MW}$ can be delivered. The settling chamber pressure and enthalpy can reach maximal values of 1000 bar and $18 \mathrm{MJ} / \mathrm{kg}$. Run durations up to 200 ms can be achieved but with decreasing reservoir conditions. The nozzle \#2 exit diameter is $0.7 \mathrm{~m}$. The test gas can be synthetic air, nitrogen or carbon dioxide.

VKI Longshot is a free piston shock tunnel, operating with nitrogen or carbon dioxide. With nitrogen, the test duration is $25 \mathrm{~ms}$. The nominal Mach number is 14 and due to very high stagnation pressure (up to 1500 bar), high values of the unit Reynolds number can be reached (up to 15 millions). The nozzle exit diameter is $0.6 \mathrm{~m}$.

Located at DLR Göttingen, HEG is also a free pistondriven shock tunnel of $60 \mathrm{~m}$ total length with a nozzle exit section of $0.9 \mathrm{~m}$ diameter. The reservoir pressure and enthalpy can reach maximal values of 900 bar and $23 \mathrm{MJ} / \mathrm{kg}$. The test duration is $1 \mathrm{~ms}$ only. The Mach number is about 8 . High values up to 42 millions can be reached for the unit Reynolds number.

The hypersonic wind-tunnel H2K at DLR Cologne is a blow-down wind tunnel with test durations up to $30 \mathrm{~s}$. The maximum values for total pressure and stagnation temperature are 45 bar and $1100 \mathrm{~K}$, respectively. Five contoured nozzles of $0.6 \mathrm{~m}$ exit diameter provide a Mach number between 5 and 11 and a unit Reynolds number up to 20 millions. 


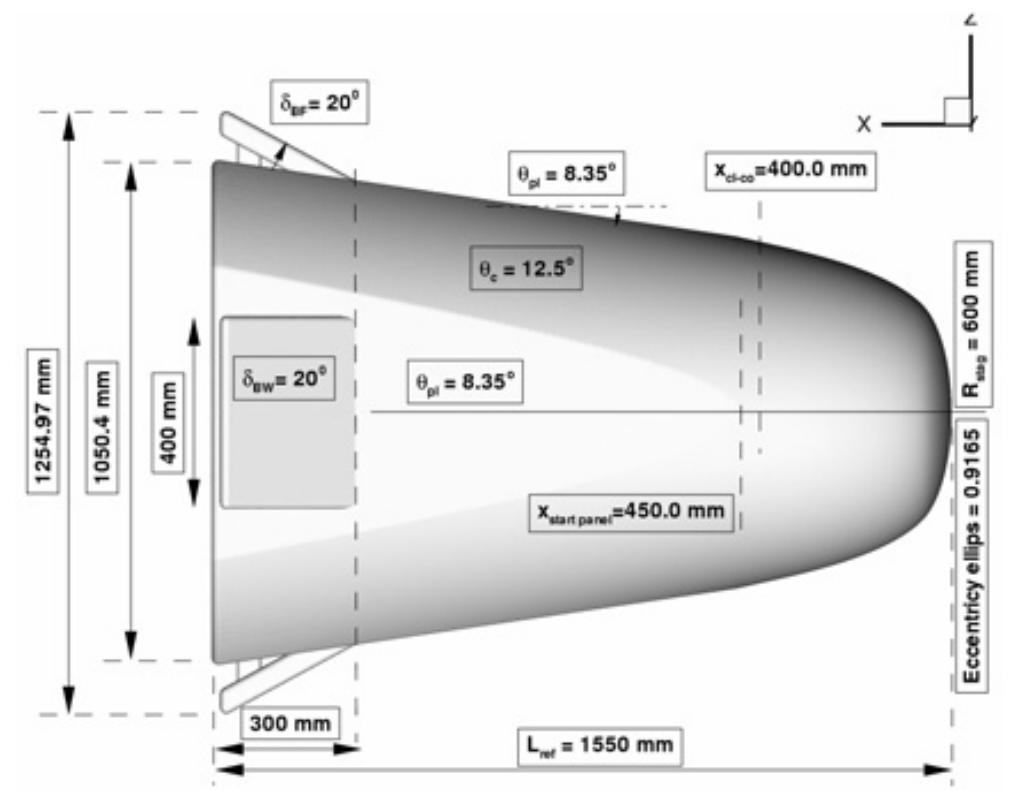

Figure 1: EXPERT 4.4 geometry, real size (from [2])

A review of non-intrusive optical measurement techniques applicable to hypersonic facilities was also performed at the beginning of the project, but except in F4 where a CO laser-diode was used to determine freeflow velocity, temperature and the mass-fraction of some chemical species, the other techniques such as electron beam fluorescence or phase-step holographic interferometry could not be used because a large part of the budget was required for models manufacturing and instrumentation.

\subsection{EXPERT models}

All the four models used are based on geometry Expert 4.4B (Fig. 1) [2], except a set of additional flaps used in H2K only, which were designed according to geometry Expert 4.5A, with minor differences compared to 4.4B. Model 1 in resin was already existing at VKI whereas the metal models 2 to 4 were designed and manufactured during HyFIE programme. Model 1 had only one double probe at the nose and it was only used for force measurements in Longshot. Model 2 included numerous pressure gauges and thermocouples. It was used for wall pressure and heat flux measurements in Longshot and for simultaneous force, wall pressure and heat flux measurements in F4. Model 3 was tested in H2K for force measurements only and had no embedded instrumentation except the balance. Model 4 was used in HEG for simultaneous force, pressure and flux measurements. The Table 1 summarizes the main properties of the models. Aerodynamic forces were measured with multicomponent balances. Due to the special force measurement system necessary for very short duration tests, HEG requires a very heavy model, made of steel, whereas the other ones were lighter and made of resin or aluminium. For models 2 and 4 , the instrumentation (pressure gauges and thermocouples) was mainly located in the forward region and on the upper and lower flaps, to investigate shock-wave / boundary-layer interaction. In this case, the Kulite pressure sensors are located on one flap and the thermocouples on the opposite flap (Fig. 9).

Table 1: models main properties

\begin{tabular}{|c|c|c|c|c|}
\hline Model & 1 & 2 & 3 & 4 \\
\hline wind-tunnel & Longshot & F4 / Longshot & H2K & HEG \\
\hline design & VKI & VKI & DLR & DLR \\
\hline manufacturing & Sirris & CMA & DLR & ITAM \\
\hline material & resin & aluminium & aluminium & steel \\
\hline scale & $1 / 6.77$ & $1 / 6.77$ & $1 / 9$ & $1 / 5$ \\
\hline length $(m m)$ & 228.7 & 228.7 & 172.2 & 310 \\
\hline ref. surface $\left(\mathrm{m}^{2}\right)$ & 0.02586 & 0.02586 & 0.01466 & 0.04751 \\
\hline weight $(\mathrm{kg})$ & 0.670 & 2.2 & 1.5 & 35 \\
\hline thermocouples & 1 & 21 & - & 6 \\
\hline pressure gauges & 1 & 11 & - & 10 \\
\hline
\end{tabular}


Table 2: free flow conditions achieved for the tests

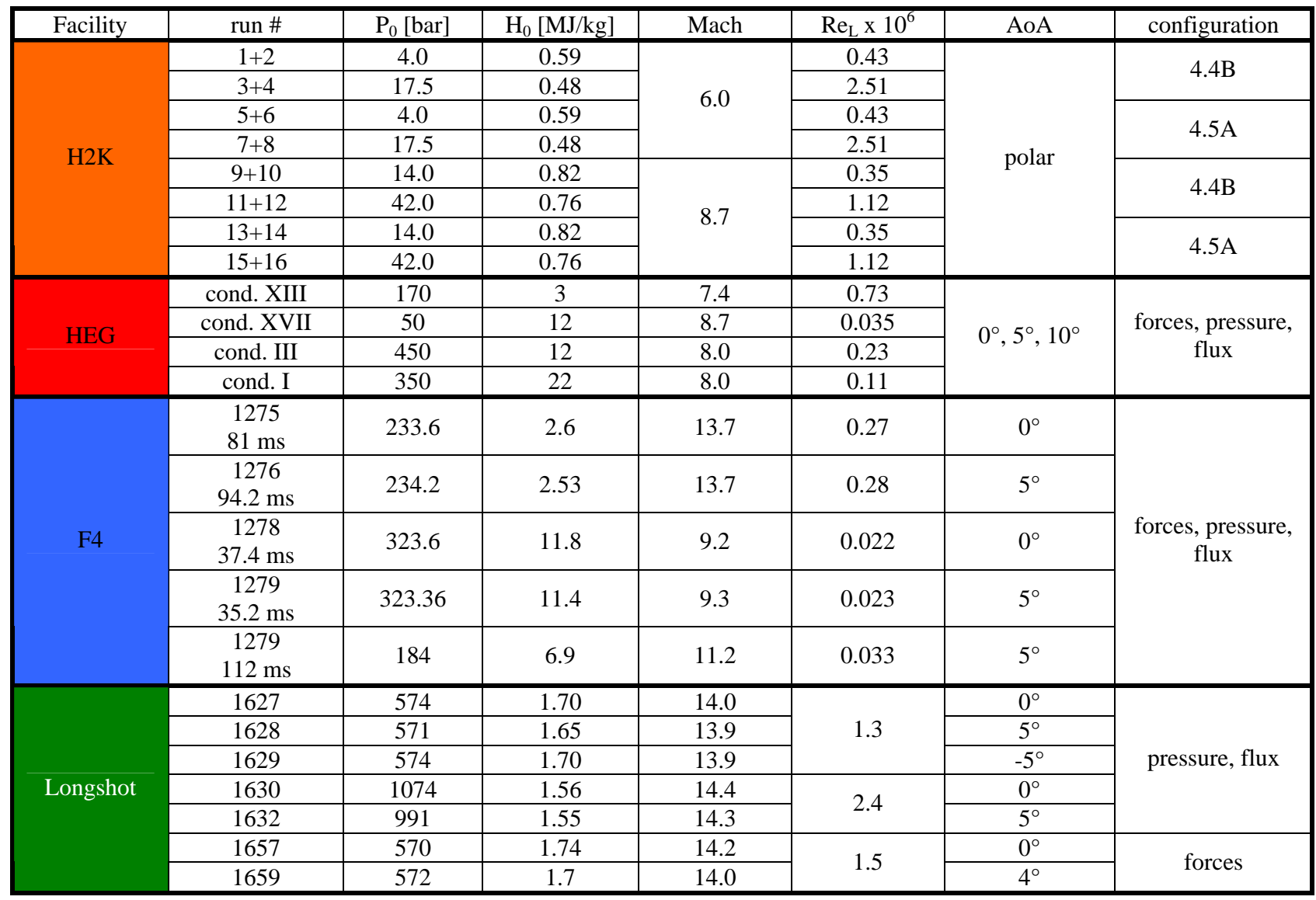

\subsection{Test matrix}

The Table 2 presents the different test conditions achieved in the four facilities. For hot facilities (HEG and F4), these free-flow conditions were obtained from measured reservoir conditions and test section probes through numerical rebuilding of the non-equilibrium flow in the nozzle. Optical devices such as laser diodes were also used. Taking advantage of the long run duration in $\mathrm{H} 2 \mathrm{~K}$, the angle of attack is varied continuously between 0 and 10 degrees during the run.
In HEG, each test is repeated for three different values of the angle of attack. For F4 tests, since the reservoir conditions vary with time, the test conditions are associated with a reference time. Two different times have been selected on the same run 1279. In Longshot, angles of attack of +5 and -5 degrees allowed to investigate both pressure and heat flux distribution on the windward side. However, the angle of attack for force measurement was limited to 4 degrees because of balance capacity.

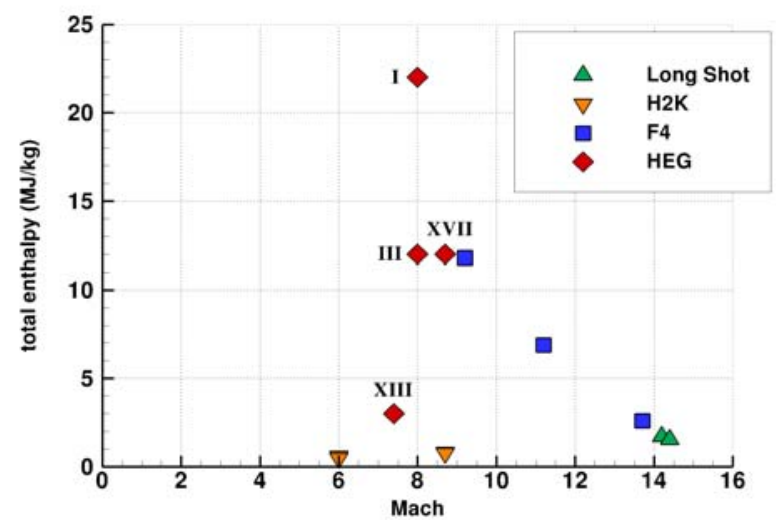

Figure 2: Mach - enthalpy test conditions

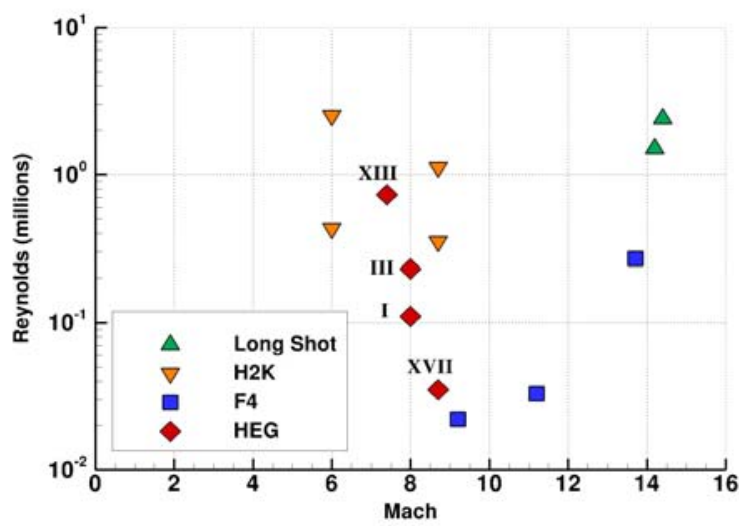

Figure 3: Mach - Reynolds test conditions 


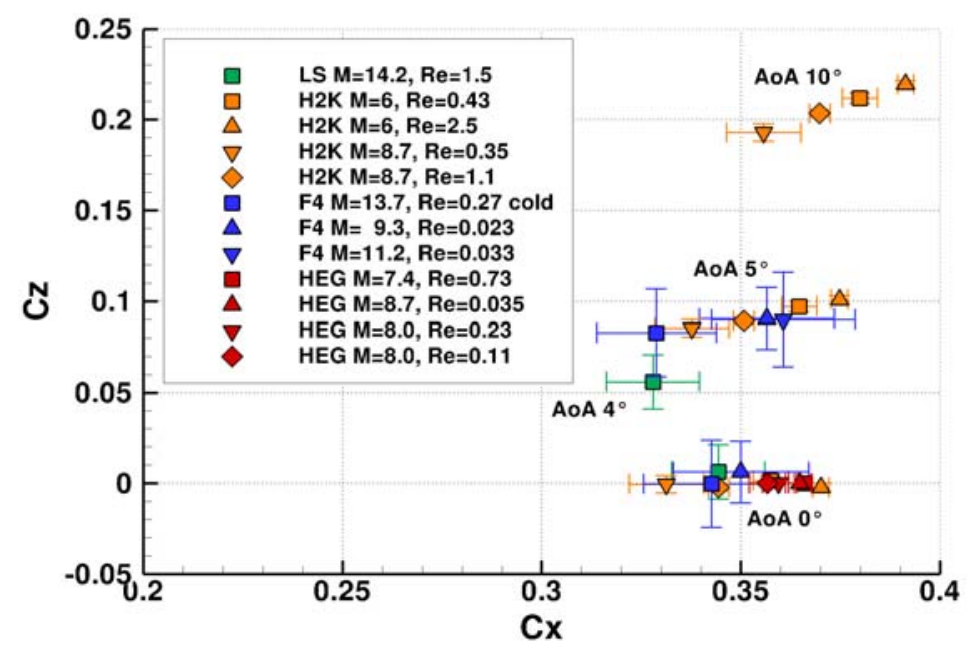

Figure 4: measured aerodynamic coefficients, $C x-C z$

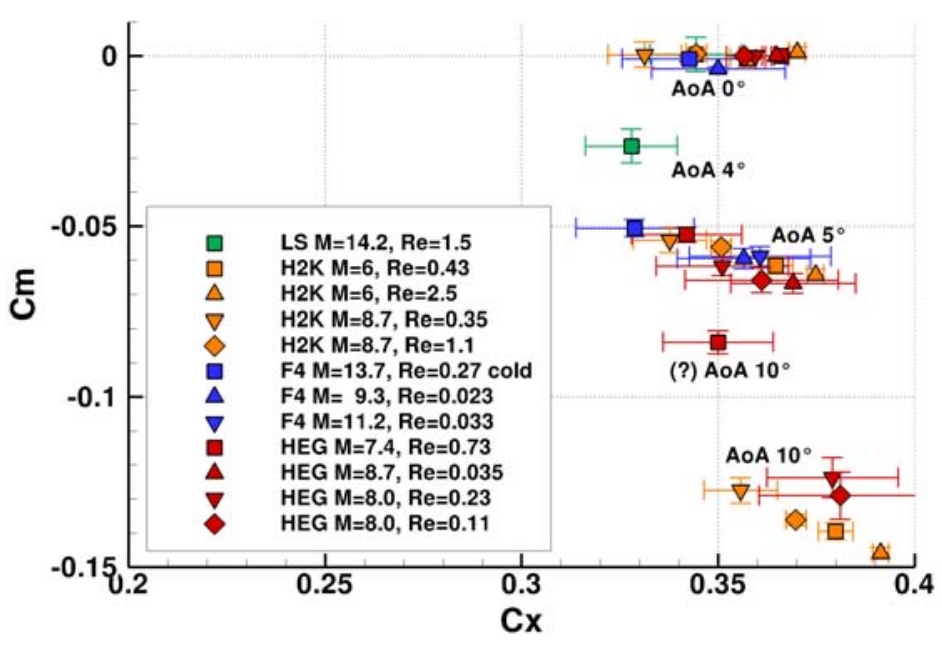

Figure 5: measured aerodynamic coefficients, $\mathrm{Cx}-\mathrm{Cm}$

The goal was to have some comparison points as close as possible between two facilities: H2K and HEG in cold conditions, HEG and F4 in hot conditions, F4 and Longshot in cold conditions. As depicted in Fig. 2, where all the test conditions have been summarized, this aim can be reached for Mach and enthalpy values, but departures still exist on the Reynolds number (Fig. 3).

\subsection{Computations}

Ten cases have been selected for computations, addressing the four test facilities, in hot reacting gas or cold perfect gas conditions. Among them, eight cases were computed with ONERA's code CELHyO $3 D$ and eight cases with DLR's code TAU, allowing several code-to-code comparisons. Both codes solve threedimensional non-equilibrium Navier-Stokes equations. CELHyO uses multi-block structured meshes whereas TAU uses unstructured meshes.

\section{SYNTHESIS OF THE TEST CAMPAIGNS}

\subsection{Aerodynamic coefficients}

The values of the lift, drag and pitching moment coefficients $\mathrm{Cx}, \mathrm{Cz}$ and $\mathrm{Cm}$ measured in all the windtunnels have been plotted in Fig. 4 and Fig. 5, with estimated error bars. The modified flaps tested in H2K were found to have no visible effect on the aerodynamic coefficients. Unfortunately, the value of the $\mathrm{Cz}$ coefficient could not be extracted from HEG tests. It appears that all the values but one (labelled “?”) are coherent, with a real precision often better than the error bars. This fact gives a good confidence in the balance processing algorithms, in spite of run durations often very short. The small departures can be due to Mach, Reynolds or total enthalpy effects. 


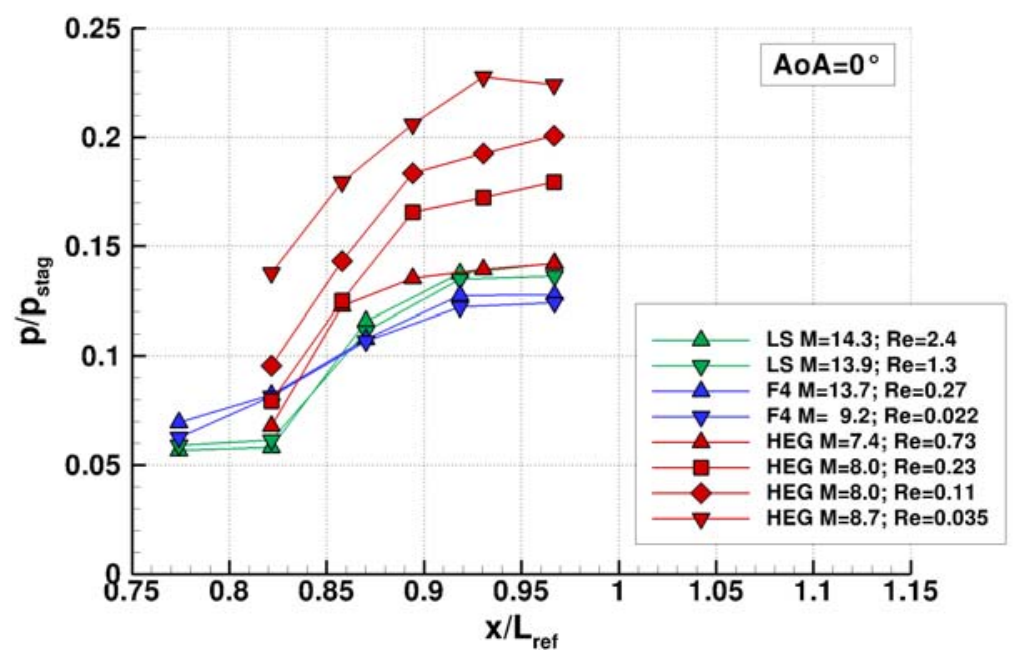

Figure 6: pressure measurements on the flaps at 0 degree angle of attack

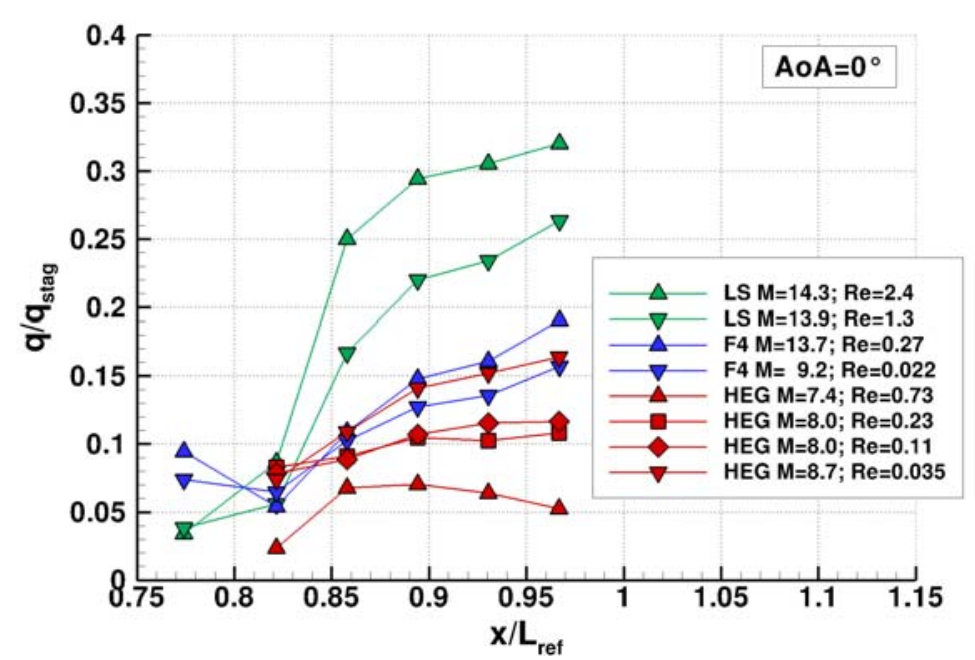

Figure 7: heat flux measurements on the flaps at 0 degree angle of attack

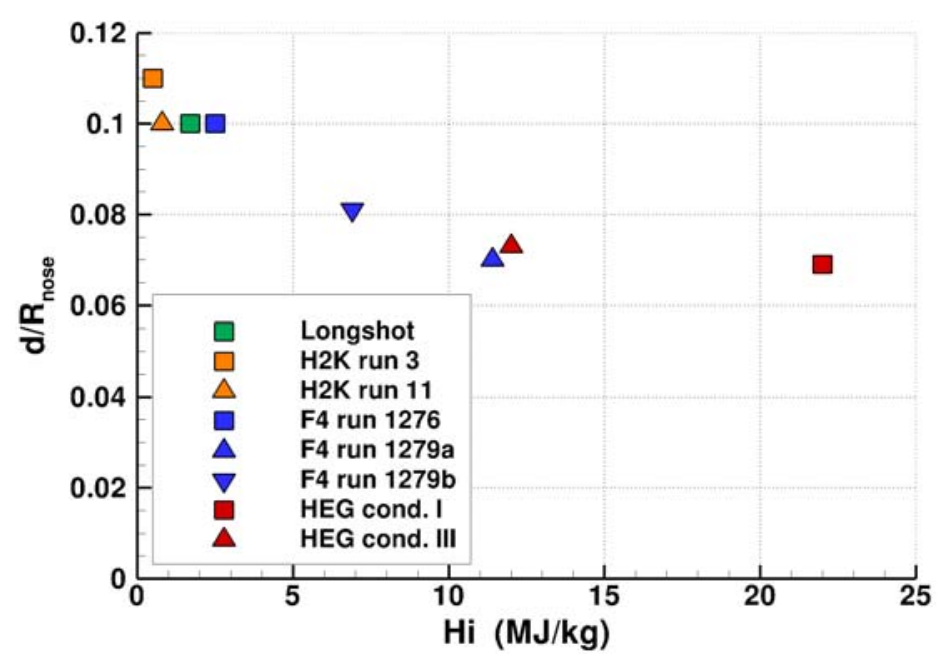

Figure 8: non-dimensional shock stand-off distance along the model x-axis at 5 degrees angle of attack 


\subsection{Wall pressure and heat flux}

The values of the wall pressure and heat flux on the flaps for all the tests performed at 0 degree angle of attack are summarized in Fig. 6 and Fig. 7, respectively. The values are referred to the corresponding values measured at the model stagnation point. The flap hinge is located at the abscissa $x / L_{r e f}=0.8$. The pressure distributions (Fig. 6) are generally in close agreement for F4 and Longshot but HEG tests show a different dependence. More differences are observed on the heat flux (Fig. 7), where F4 and Longshot see an increase of the heat flux with the Reynolds number whereas HEG shows an opposite tendency. It can be also noticed that the pressure values for the nearly common test point between HEG $(\mathrm{M}=8.7$; Re = 0.035) and F4 $(\mathrm{M}=9.2$; $\mathrm{Re}=0.022$ ) disagree (Fig. 6) whereas the heat flux values for the same case agree (Fig. 7). These results represent a partial view of the complex phenomena occurring near the flap hinge: boundary-layer separation, interaction with the shock waves, possible laminar-turbulent transition, and reattachment. More information can be deduced from the computations.

\subsection{Real gas effects}

The departure from perfect-gas behaviour can be observed at high enthalpy, where chemical reactions and thermochemical non-equilibrium induce a modification of the shock stand-off distance at the nose. This parameter, which is known to be very sensitive to realgas effects, has been measured on Schlieren pictures taken during the tests and plotted in Fig. 8 as a function of the total enthalpy, showing a progressive decrease from the perfect-gas value, close to 0.1 , in cold facilities, to a lower value, about 0.07 , in hot facilities.

\section{SYNTHESIS OF THE COMPUTATIONS}

\subsection{Code to code comparisons}

Fruitful comparisons have been made between computed data obtained with both CELHyO and TAU codes. Fig. 9 shows an example of comparison of the wall heat flux distributions predicted by both computations on an F4 high-enthalpy test case, with 5 degrees angle of attack. The agreement is fine, except that TAU predicts a slightly lower heat flux in the nose region. The positions of the pressure (light blue) and temperature (yellow) sensors have also been plotted. The nose probe is a double probe measuring both pressure and temperature.

A closer view on the windward side flap is depicted in Fig. 10, where the wall pressure coefficient has been plotted for both computations. The agreement is excellent, as well as the geometry of the separated bulb delimitated by the friction lines. This kind of phenomenon is known to be very sensitive in numerical simulations and in this way the present agreement must be emphasized. The only obvious difference concerns the areas besides of the flap. This is due to slightly different geometries of the cavity below the deflected flap. It will produce noticeable effects on the wall pressure and heat flux in this region, where exist pressure and temperature sensors on Model 2.

\subsection{Code to test comparisons}

An example of comparison between experiment and computations is presented in Fig. 11 and Fig. 12, where the measured and computed aerodynamic coefficients have been plotted for H2K runs. In the present case with perfect-gas behaviour, both codes succeed to predict the aerodynamic coefficients with a very good accuracy.

A comparison between measured and computed values of the wall pressure and heat flux in F4 at the pressure gauges locations are plotted in Fig. 13 and Fig. 14, respectively. The agreement on the pressure distribution is satisfactory, in spite of the fact that the stagnation pressure at the nose is not identical in the computation and in the experiment, maybe due to some uncertainties on the free-flow determination in the experiment. Thus the agreement would be better if the pressure was referred to the nose pressure. The pressure gauges on the right part of the plot are located on the flap surface, except the two ones labelled "flap side", for which significant departures can be noticed. This is related to the differences already mentioned in Fig. 10. Higher discrepancies appear on the wall heat flux distribution (Fig. 14), where the same remarks that for the pressure apply concerning the nose value and the thermocouples located on the sides of the flap. The local heat flux decrease in the separated area close to the flap hinge is however very well predicted by both computations.

\section{CONCLUSION}

A large amount of data was collected during the four test campaigns and the two series of computations carried out from 2007 to 2012 in the frame of HyFIE TRP, initiated and funded by ESA. The common Expert geometry adopted for the whole project, the definition of a test plan with common test points allowing comparisons between different facilities and the use of two different computation codes TAU and CELHyO provide large possibilities of comparisons, code to code, code to wind-tunnel and wind-tunnel to wind-tunnel. A large domain of flow conditions, enthalpy, Mach and Reynolds numbers, has been explored in the four windtunnels used. Numerous results have been presented in the final report [5].

From the experimental point of view, one of the main progress has been the confirmation of the possibility to perform simultaneous measurements of aerodynamic forces, wall pressure and wall heat flux in F4, without accelerometers inside the model. The equivalent performance was attempted in HEG but encountered difficulties due to the very short test duration and thus the lift coefficient could not be measured. In the hot 

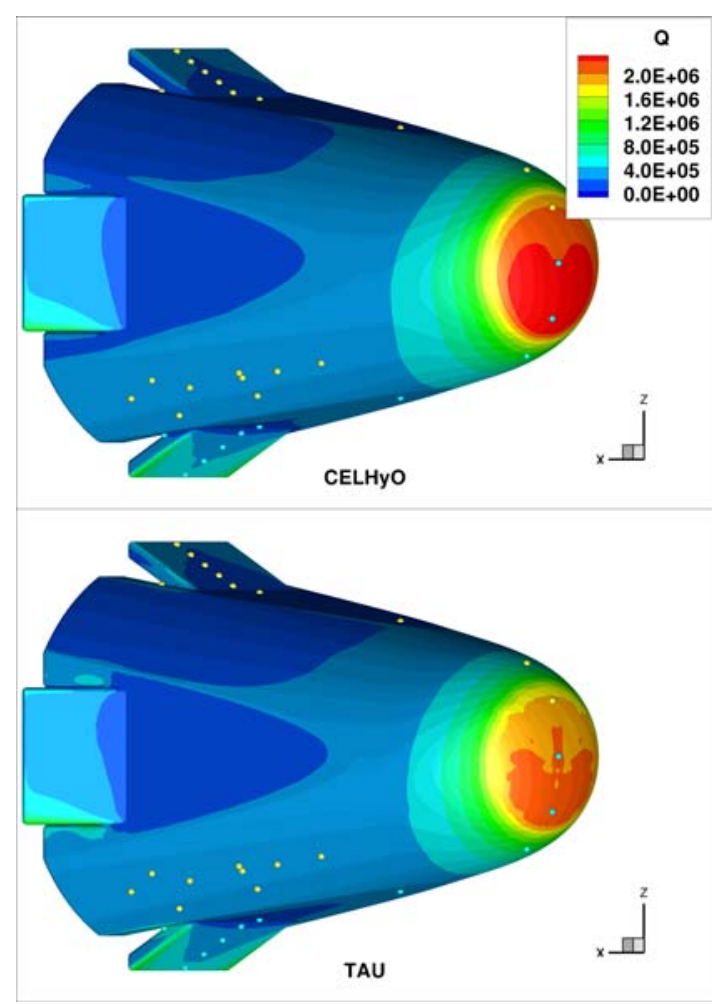

Figure 9: F4 run 1279, $t=35.2 \mathrm{~ms}$, AoA = 5 degrees, wall heat flux and probes positions ; pressure taps (light blue) and thermocouples (yellow)

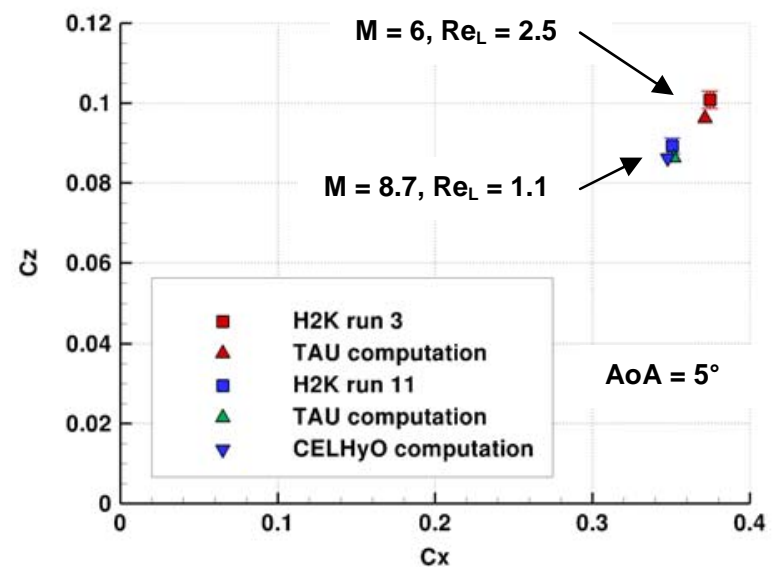

Figure 11: $C x-C z$ summary plot for $\mathrm{H} 2 \mathrm{~K}$

wind tunnels, the uncertainties on the free-stream flow still constitute a large part of the uncertainty on the measured coefficients.

The comparison between computations and experiments showed a satisfactory agreement for the prediction of global aerodynamic coefficients, but the numerical prediction of the flow around the model flaps was a more challenging problem, in particular for the case at 10 degrees angle of attack. The very complex flow developing near the flap hinge, coupled with high
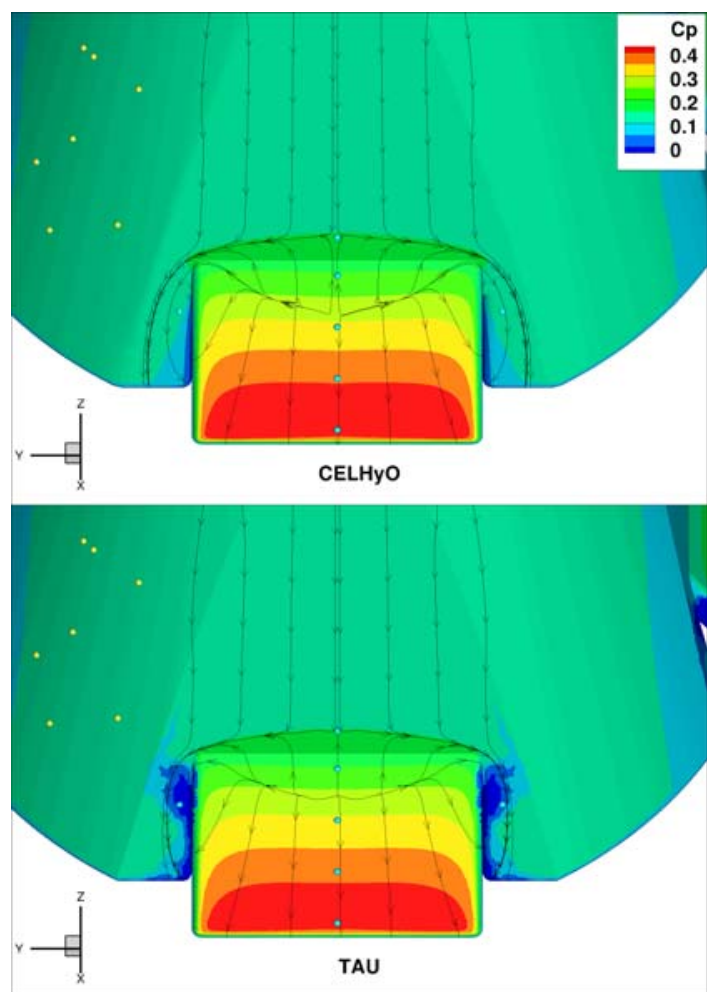

Figure 10: F4 run 1279, $t=35.2 \mathrm{~ms}$, AoA $=5$ degrees, wall pressure coefficient and friction lines on the windward flap

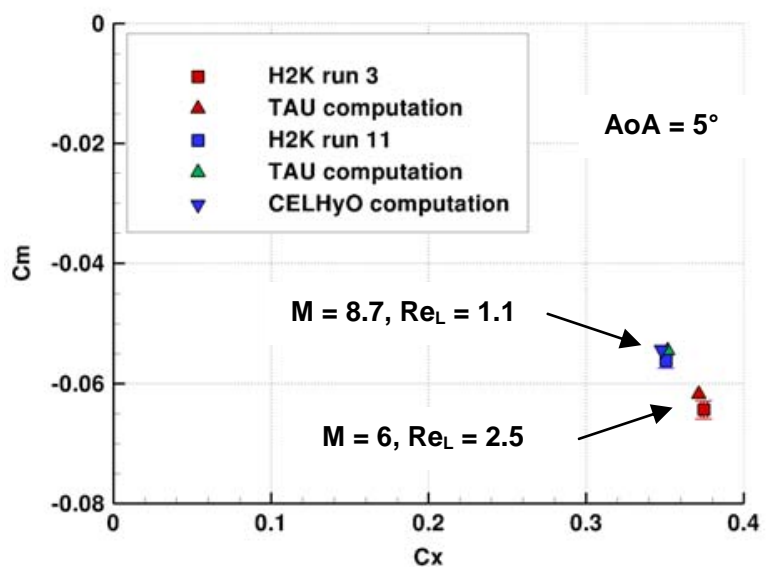

Figure 12: $\mathrm{Cx}$ - Cm summary plot for $\mathrm{H} 2 \mathrm{~K}$

enthalpy effects and wall interaction, was also difficult to investigate in the experiments. The pressure and temperature transducers fitted on the model flap give some insight on the reliability of the computations whereas the computations provide in turn some hints to understand the flow topology and interpret the experimental results. Anyway, further investigation of the numerical results is needed to understand the geometry of the separated flow on the flaps and its dependency on the flow parameters such as total enthalpy, Mach and Reynolds numbers. 


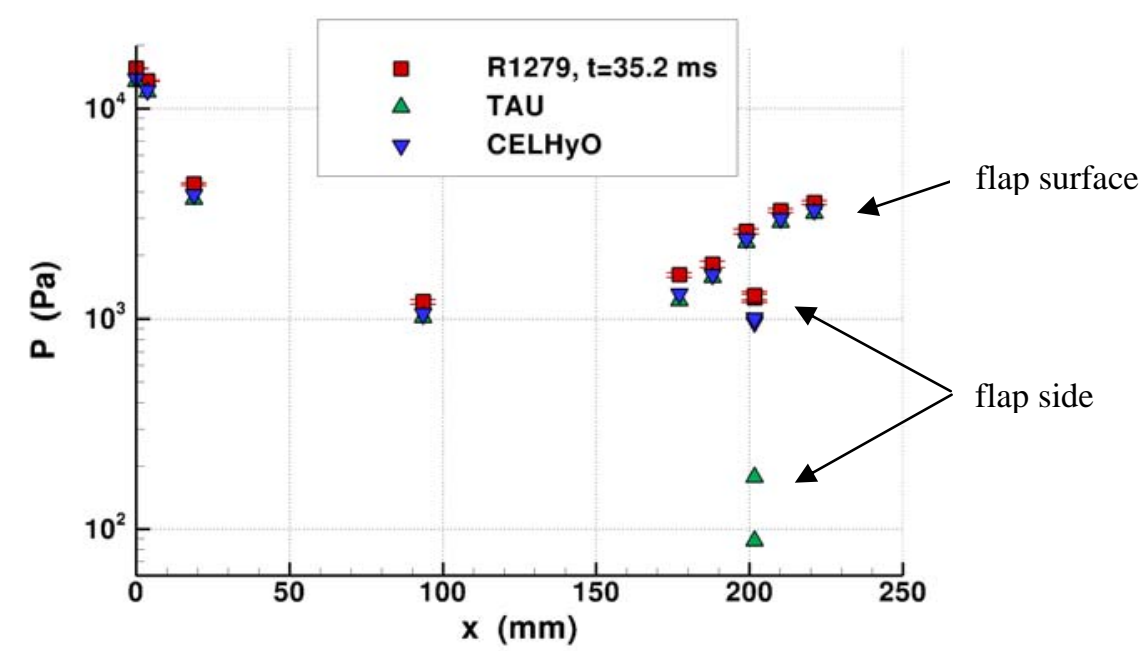

Figure 13: measured and computed wall pressure, F4 run 1279, $t=35.2 \mathrm{~ms}$

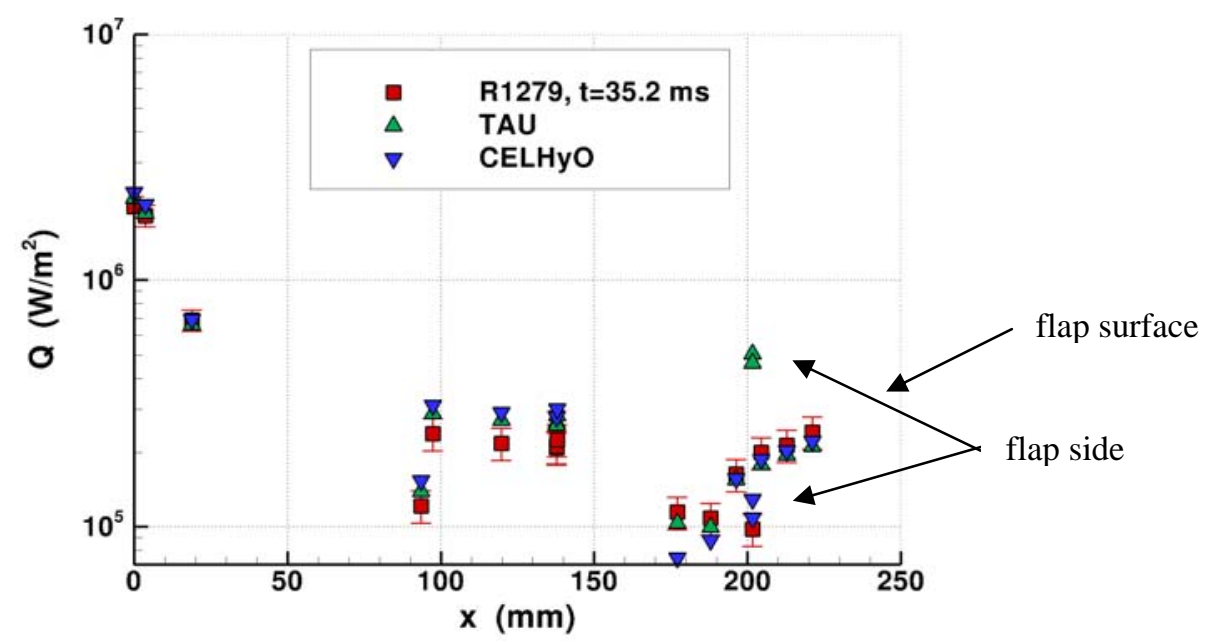

Figure 14: measured and computed wall heat flux, F4 run 1279, $t=35.2 \mathrm{~ms}$

\section{ACKNOWLEDGEMENTS}

This project was initiated and granted by ESA under contract 20719/07/NL/IA. The authors would like to thank the Project Technical Officer Louis Walpot for his interest and close support to this work.

\section{REFERENCES}

[1]. Statement of Work (2006) "Hypersonic Facility Instrumentation Enhancements for Improved Flight Extrapolation and Scaling” ESA document TEC-MPA/2006/302/JM.

[2]. Muylaert, J.-M., Ottens, H., Walpot, L., Cipollini, F., Schettino, A., Saccoccia, G., Kordulla, W., Caporicci, M. (2005). Aerothermodynamic Environment of EXPERT and Flight Measurement
Technique integration issues, $56^{\text {th }}$ International Astronautical Congress.

[3]. Muylaert, J.-M., Ottens, H., Walpot, L., Cipollini, F., Gavira, F., Marino, G., Caporicci, M. (2006). EXPERT aerothermodynamic flight instrumentation environment and integration, $57^{\text {th }}$ International Astronautical Congress

[4]. Massobrio, F., Viotto, R., Serpico, M., Sansone, A., Caporicci, M., Muylaert, J.-M. (2007). EXPERT: An atmospheric re-entry test-bed, Acta Astronautica, 60 (12), 974-985

[5]. Brazier, J.-Ph., Martinez Schramm, J. (2012) Technical Research Project HyFIE - Hypersonic Facility Instrumentation Enhancements for Improved Flight Extrapolation and Scaling: deliverable D6 - final report 